 \\ 詁IERE SPACQ
}

\section{O RURAL E O URBANO NO MARANHÃO MERIDIONAL: apontamentos a partir da Região Geográfica Intermediária de Imperatriz}

\author{
RURAL AND URBAN IN THE SOUTHERN MARANHÃO: points from the \\ Geographical Intermediary Region of Imperatriz
}

\section{RURAL Y URBANO EN EL MARANHÃO MERIDIONAL: notas de la Región Geográfica Intermedia de Imperatriz}

\begin{abstract}
Helbaneth Macêdo Oliveira
Doutoranda em Geografia pela Universidade Federal de Uberlândia - PPGEO/IG//UFU. Membro do grupo de pesquisa Sul Global e Novas Dinâmicas Urbanas e do Observatório de Políticas Territoriais e Educacionais. helbaneth@hotmail.com / http://orcid.org/0000-0003-0770-0598
\end{abstract}

Recebido para avaliação em 06/11/2019; Aceito para publicação em 10/06/2020.

\section{RESUMO}

O presente artigo consiste em compreender a porção sul do estado do Maranhão, adjetivada aqui por Região Intermediária de Imperatriz, a qual está inserida no contexto da Amazônia Oriental e partícipe das políticas públicas de integração do território nacional, tendo a construção da Rodovia Belém-Brasilia como um dos projetos que impactaram diretamente a urbanização do sul maranhense. Observando estas colocações se pontua que a Região Intermediária de Imperatriz é composta por quatro regiões imediatas, as quais fornecem subsídios para se entender a dinâmica regional em recorte. Assim, o estudo objetiva então fornecer as bases para a compreensão da Região Intermediária de Imperatriz, observando suas regiões imediatas e, para isso, se fez uma discussão sobre o rural e o urbano. Posteriormente se apresenta brevemente o processo histórico de constituição do Sul do Maranhão, para então levantar uma identificação geral, apresentando dados populacionais, de área territorial, bem como a distribuição do PIB nos três setores da economia, tudo isso no intuito de se evidenciar a importância da Região Intermediária de Imperatriz.

Palavras-chave: Rural e Urbano; Região Intermediária de Imperatriz; Sul do Maranhão.

\section{ABSTRACT}

The present article consists of understanding the southern portion of the state of Maranhão, hereby adjective called Imperatriz Intermediate Region, which is inserted in the context of the Eastern Amazon and, participant of the public policies of integration of the national territory having the construction of Belém-Brasília Highway as one of the projects that directly impacted the urbanization of Southern Maranhão. Observing these statements, it is pointed out that the Imperatriz Intermediate Region is composed of four immediate regions, which provide subsidies to understand the regional dynamics. Thus, the study aims to provide the basis for the understanding of the Imperatriz Intermediate Region by observing its immediate regions and, for this, a discussion about the rural and urban areas is presented, afterwards the historical process of constitution of Southern Maranhão is briefly presented. In order to obtain a general identification, presenting population data, of territorial area, as well as the distribution of PIB in the three sectors of the economy, all in order to highlight the importance of the Imperatriz Intermediate Region. 
| O rural e o urbano no Maranhão Meridional: apontamentos a partir da Região Geográfica Intermediária de Imperatriz|

| Helbaneth Macêdo Oliveira |

Keywords: Rural and Urban; Intermediate Region of Imperatriz; Southern Maranhão.

\section{RESUMEN}

El presente artículo consiste en comprender la parte sur del estado de Maranhão, denominada aquí como Región Intermedia de Imperatriz, que se inserta en el contexto de la Amazonía Oriental y participa de las políticas públicas de integración del territorio nacional, teniendo en la construcción de la carretera Belém-Brasilia, uno de los proyectos que impactaron directamente la urbanización del sur del estado. Siguiendo estas declaraciones, se señala que la Región Intermedia de Imperatriz está compuesta por cuatro regiones inmediatas, que proporcionan subsidios para comprender la dinámica regional seleccionada. Por lo tanto, este artículo tiene como objetivo proporcionar la base para comprender la Región Intermedia de Imperatriz, observando sus regiones inmediatas, presentando para esto una discusión sobre lo rural y lo urbano, y una breve contextualización del proceso histórico de constitución del sur de Maranhão, con el fin de obtener una identificación general. Se usan datos de población, del área territorial, así como la distribución del PIB en los tres sectores de la economía, para resaltar la importancia de la Región Intermedia de Imperatriz.

Palabras clave: Rural y Urbano; Región Intermedia de Imperatriz; Maranhão del Sur.

\section{ARGUMENTOS INICIAIS}

As novas configurações do espaço rural têm sido um desafio enfrentado por muitos pesquisadores na contemporaneidade. A leitura desse espaço requer entender também as novas relações construídas no campo e que, em muito, relacionam-se com o urbano manifesto nas cidades. Com a densificação do capital global, torna-se mais complexa a relação campo-cidade, apresentando novas nuances, novos arranjos produtivos, novas funções e significados que impulsionam a produção da mais valia global.

Neste sentido, este trabalho concorda com Santos (2017) ao afirmar que todos os espaços são globais, em maior ou menor proporção e, neste ínterim, o estado do Maranhão também está inserido, com suas particularidades e ambiguidades. Daí que, a porção meridional do Maranhão ${ }^{1}$ é objeto deste estudo, tendo em vista apresentar todo um processo histórico de constituição diferenciado do restante do estado, o que reflete também em uma constituição socioeconômica e urbana específica. Sendo importante apontar que, estudar tal espaço é fundamental para se compreender a forma e a dinâmica das relações cidade-campo no processo de reprodução do capital.

Observando esta dinâmica diferenciada, escolheu-se aqui por trabalhar com a delimitação deste espaço a partir dos limites constitutivos da Região Geográfica Intermediária de Imperatriz, regionalização esta desenvolvida pelo Instituto Brasileiro de Geografia e Estatística - IBGE e publicada em 2017. Esta região intermediária abrange a maior parte da porção sul do estado e, por isso, acredita-se que sua leitura possa oferecer

\footnotetext{
${ }^{1}$ Destaca-se que esta mesma área é comumente chamada de região Tocantina do Maranhão, tendo em vista que faz parte da região popularmente chamada de Tocantina (abrange o norte do estado do Tocantins, o leste do Pará e o oeste do Maranhão), que é delimitada pelo percurso do rio Tocantins.
} 
| O rural e o urbano no Maranhão Meridional: apontamentos a partir da Região Geográfica Intermediária de Imperatriz|

| Helbaneth Macêdo Oliveira |

ricas contribuições sobre o Maranhão Meridional. Sendo relevante expor que a mesma é constituída por quatro regiões imediatas² (Imperatriz, Balsas, Açailândia e Barra do Corda), as quais o estudo estará pormenorizando.

Diante disso, o objetivo basilar do trabalho consiste então em compreender o rural e o urbano no Maranhão Meridional, tendo como ponto de partida a Região Geográfica Intermediária de Imperatriz e suas regiões imediatas. Para isso procurar-se-á apresentar uma identificação geral da área, sua dinâmica socioeconômica e seu processo histórico de formação socioespacial. Procurando evidenciar a contribuição do Sul do Maranhão para a dinâmica do estado.

Observando o que se pretende alcançar, o percurso metodológico adotado parte da construção de uma revisão bibliográfica, na qual se discute a relação do rural e do urbano, os principais teóricos sobre o Sul do Maranhão e seu processo histórico de formação, para posteriormente apresentar a identificação da Região Geográfica Intermediária de Imperatriz, por meio do levantamento de dados secundários como população total, população rural/urbana, extensão territorial, densidade demográfica e o PIB distribuído pelos principais setores econômicos.

Por conseguinte, o artigo está estruturado em três seções, excetuando-se às presentes argumentações iniciais e as considerações finais. A primeira seção vem tratar das principais vertentes contemporâneas da relação rural-urbano; a segunda seção explica como ocorreu e de que forma a urbanização da porção sul do Maranhão influiu para a estruturação da Região Intermediária de Imperatriz; e a terceira e última seção apresenta a identificação da região em estudo diante de uma ênfase às particularidades de suas respectivas regiões imediatas.

\section{REFLEXÕES SOBRE O RURAL E O URBANO}

Diante das constantes transformações ocorridas no espaço, a emergência da globalização tem sido o prisma para a leitura de muitos dos processos materializados no campo e na cidade, confluindo para a necessidade de uma visão mais acurada no que se refere ao entendimento dos espaços urbanos e rurais. Pensando assim, acredita-se que os espaços da globalização definidos por Santos (2017) como possuidores de conteúdos, tanto técnico, informacional quanto comunicacional, constituem-se aportes fundamentais para qualquer estudo vinculado à realidade do campo e da cidade.

2 “As Regiões Geográficas Imediatas têm na rede urbana o seu principal elemento de referência. Essas regiões são estruturas a partir de centros urbanos próximos para a satisfação das necessidades imediatas das populações [...]" (IBGE, 2017, p. 20, grifo nosso). 
| O rural e o urbano no Maranhão Meridional: apontamentos a partir da Região Geográfica Intermediária de Imperatriz|

| Helbaneth Macêdo Oliveira |

É importante pontuar que, no presente estudo, se ver o campo e a cidade pela perspectiva desenvolvida por Locatel (2013), que observa estes espaços enquanto construções sociais, logo reafirma-se a condição de subespaços produzidos no bojo das relações sociais. Assim sendo, para se entender o rural e o urbano carece entender a dinâmica apontada por Santos (2017) ao tratar do binômio forma-conteúdo, visto que se compreende o rural enquanto conteúdo de uma forma - o campo. Da mesma forma, interpreta-se o urbano enquanto conteúdo materializado, principalmente, no espaço das cidades.

Há que se abrir um parêntese na questão citada, pois muitos estudos vêm apontando a presença de "urbanidades" no campo e, também, "ruralidades" nas cidades, conteúdos distintos dos costumeiros destes espaços. A discussão, acreditamos, ter sua explicação, na ampliação reprodutiva do capital global. Não se observa aqui a anulação do campo em detrimento da cidade, pois, "no campo e na cidade, vão se construindo territórios do capital, mas sem destruir todas as formas preexistentes que, ao se metamorfosearem, encontram maneiras de resistir e persistir, enquanto outras são criadas" (SUZUKI, 2009, p. 251).

Seria reducionista de nossa parte simplificar a identificação do rural apenas ao que não é urbano, pois perder-se-ia toda uma gama de atributos e relações que este possui, privilegiando-se o urbano. Da mesma forma, não se concorda com a vertente clássica pela qual o campo é visto, identificada por Carneiro (2008), em que o conteúdo identitário do campo seria dado apenas pela presença ou não do agrário, tendo em vista tão somente a produção. Ao tratar do urbano e rural enquanto categorias, a autora citada é assertiva em explicar a riqueza metodológica encontrada no rural enquanto categoria realizada, de onde se apreende muitos processos e interações, que trazem novos significados a partir dos atores construtores deste espaço.

Não se pode negar que, “a sociedade e a vida urbana, conduzidas pela expansão urbana, penetram no campo. Assim, pode-se entender a urbanização como um processo de transformação que afeta tanto a cidade quanto o campo [...]” (LOCATEL, 2013, p. 93). Ou seja, acolhe-se a concepção do urbano enquanto conteúdo que tem se estendido para além dos limites da cidade, no entanto, sua interação com o rural em muito tem proporcionado a reprodução da mais valia em ambos. Assim, percebe-se que:

O espaço local é, por excelência, o lugar da convergência entre o rural e o urbano, no qual, as particularidades de cada um não são anuladas; ao contrário, são a fonte da integração e da cooperação, tanto quanto da afirmação dos interesses específicos dos diversos atores sociais em confronto. O que resulta dessa aproximação é a configuração de uma rede de relações recíprocas, em 
| O rural e o urbano no Maranhão Meridional: apontamentos a partir da Região Geográfica Intermediária de Imperatriz|

| Helbaneth Macêdo Oliveira |

múltiplos planos que, sob muitos aspectos, reitera e viabiliza as particularidades. (WANDERLEY, 2009, p. 233-234).

A colocação confirma a assertiva sobre quão importante é a aproximação do rural com o urbano, desmistificando a visão hierárquica do campo enquanto resíduo do urbano. $\mathrm{Na}$ verdade, se entende essa aproximação como uma necessidade do capital, gerando o que Santos (2017) vai chamar de "guerra dos lugares", consistindo numa acirrada competição dos lugares para criar novas atividades geradoras de riquezas, em que os lugares chegam a utilizar-se dos recursos (materiais e imateriais) que possui para a reprodução do capital. Daí a presença de "urbanidades" no rural, tais como as novas formas de se utilizar do campo (como é o caso do turismo de contemplação e das comodidades urbanas como a internet) e, também, das "ruralidades" no urbano, tal como o é os momentos e locais especializados na cultura country.

Nesse sentido, para além de pura e simples dicotomia cidade-campo ou mesmo urbano-rural, a visão aqui adotada compartilha da perspectiva de Rua (2005), ao pontuar que:

\footnotetext{
Assim espaço rural e espaço urbano, cidade e campo integram-se à mesma racionalidade espacial que marca a sociedade contemporânea, organizada a partir da cidade, da indústria e, atualmente, da terciarização - bases operativas privilegiadas para a reprodução do capitalismo em sua produção histórica e para a constituição da visão burguesa de mundo. Este processo transescalar tem abrangido o planeta (Ocidentalização do Mundo), a nação (hegemonia do Sudeste urbano-industrial) e a multiescalaridade das relações cidade-campo todas elas dicotômicas, hierarquizadoras e polarizadoras (RUA, 2005, p. 47).
}

Essa racionalidade do espaço preconizada por Santos (2017) constitui-se em um dos fatores de conexão do campo com a cidade, ambos estão inseridos na lógica de produção global, logo sujeitos aos ditames do capital que coordena a relação dos lugares em diversas escalas de ação. Processo esse que, longe de ser simples, apresenta contradições que dificultam entender como o rural e o urbano se inter-relacionam e, ao mesmo tempo, recriam-se e afirmam-se por meio de novas identidades e ações. Logo, sobre isso se frisa que no campo:

[...] esse processo contraditório e desigual de desenvolvimento da agricultura, sobretudo via sua industrialização, tem eliminado gradativamente a separação entre a cidade e o campo, entre o rural e o urbano, unificando-os numa unidade dialética. Isso quer dizer que campo e cidade, cidade e campo formam uma unidade contraditória. [...] tudo indicando que ele mesmo (o capitalismo) está fundindo a união contraditória que separou no início de sua expansão: a agricultura e a indústria; a cidade e o campo. [...] A cidade, hoje, revela essas contradições. Ela é, pois, o palco e o lugar dessas lutas rurais/urbanas e/ou urbanas/rurais. O que significa dizer que a compreensão dos processos que atuam na construção/expansão de grande parte das cidades passa pela 
| O rural e o urbano no Maranhão Meridional: apontamentos a partir da Região Geográfica Intermediária de Imperatriz|

| Helbaneth Macêdo Oliveira |

igualmente necessária compreensão dos processos que atuam no campo (OLIVEIRA, 2004, p. 64).

Ademais, a evidência na relação contemporânea do rural e do urbano encontra-se então no destaque do caráter híbrido do espaço. Criando-se novas interdependências, conforme citou Oliveira (2004), sendo que a cidade torna-se reveladora dessa nova forma de produção, mas que, devido sua íntima relação com o rural, torna-se necessário também entender as novas nuances do campo. Essa relação campo-cidade adota agora contornos mais pungentes de um processo que é global, por meio dos imperativos que o mercado implanta no campo e na cidade sob formas próprias de reprodução do capital, evidenciando o urbano e o rural enquanto faces de uma mesma moeda.

Prosseguindo o estudo, a próxima seção procura evidenciar o processo histórico de constituição da porção sul do estado do Maranhão, onde se localiza o recorte espacial da pesquisa. O sentido do que se apresenta consiste em explicar então, como o campo se transforma ao passo que as cidades foram adquirindo destaque, e como a dinâmica da Região Intermediária de Imperatriz apresenta estes aspectos.

\section{ASPECTOS DA FORMAÇÃO SOCIOESPACIAL DO MARANHÃO MERIDIONAL}

Apresentar o processo de formação socioespacial da porção sul do Maranhão não é uma tarefa fácil. A urbanização do território maranhense remonta o século XVI, partindo do litoral onde encontra-se São Luís, a capital do estado e também a única cidade brasileira fundada por franceses. No entanto, no que tange ao Sulmaranhense ${ }^{3}$, a história desenvolvese de outra forma, pois só depois de longo período de tempo esta área passa a ser foco de atenção.

Foi somente por volta do Século XVIII que as primeiras correntes de povoamento chegaram ao interior do Maranhão, tendo o gado como apoio principal. Dentre os estudiosos do sul do Maranhão, Sousa (2015) comenta sobre isso que:

Os criadores de gado lançaram-se à conquista do sertão desconhecido.
Instalaram-se às margens ribeiras do Parnaíba, no contato direto com os rios
Manoel Alves Grande e do Tocantins e estabeleceram nesta região diversas
fazendas. Esses vaqueiros dedicaram-se, especialmente, à criação de gado. Trata-
se da emergência de uma sociedade marcada por valores socioculturais distintos
do litoral. Com isto, observou-se a instalação de vilas e núcleos de povoamento

3 Sulmaranhense é o termo cunhado por Sousa (2015) em seus estudos regionais para referir-se à Região Tocantina do Maranhão, no entanto, o IBGE (1980) também apresentou o termo Sul Maranhense como uma mesorregião que abrangia apenas 19 municípios da porção sul do estado. 
| O rural e o urbano no Maranhão Meridional: apontamentos a partir da Região Geográfica Intermediária de Imperatriz|

| Helbaneth Macêdo Oliveira |

dispersos pelo Maranhão meridional. Este movimento orientou-se da região sul em direção ao oeste do estado, obedecendo aos caminhos guiados pelo gado (SOUSA, 2015, p. 113).

Diferentemente do norte do Maranhão, a porção sul tem na criação de gado a atividade que subsidiou a conquista deste vasto território, conforme afirma a colocação, e muito se diferencia do restante do estado. Esta área também foi denominada de "Pastos Bons" ou mesmo "Sertão de Pastos Bons", dada à abundância de campos e diversas riquezas naturais como a presença de nascentes e água em abundância, além de uma variedade de árvores frutíferas (CARVALHO, 2006).

Falar dos Sertões de Pastos Bons (Vide Mapa 1) é então resgatar um pouco da história do sul do Maranhão, pois foi a partir desta que tem-se a identificação deste território. Mesmo assim, por muito tempo a área ficou isolada da capital São Luís. Conforme relatam Franklin e Sousa (2013), Carolina, Porto Franco e Imperatriz foram por muito tempo não somente as únicas povoações às margens do rio Tocantins, como também, isoladas até por volta da metade do século XX sem conexão com o restante do estado, sendo o rio a única forma de acesso, além das longas e dificultosas viagens com o uso de animais, daí as estreitas vinculações destas com os estados de Goiás e Pará.

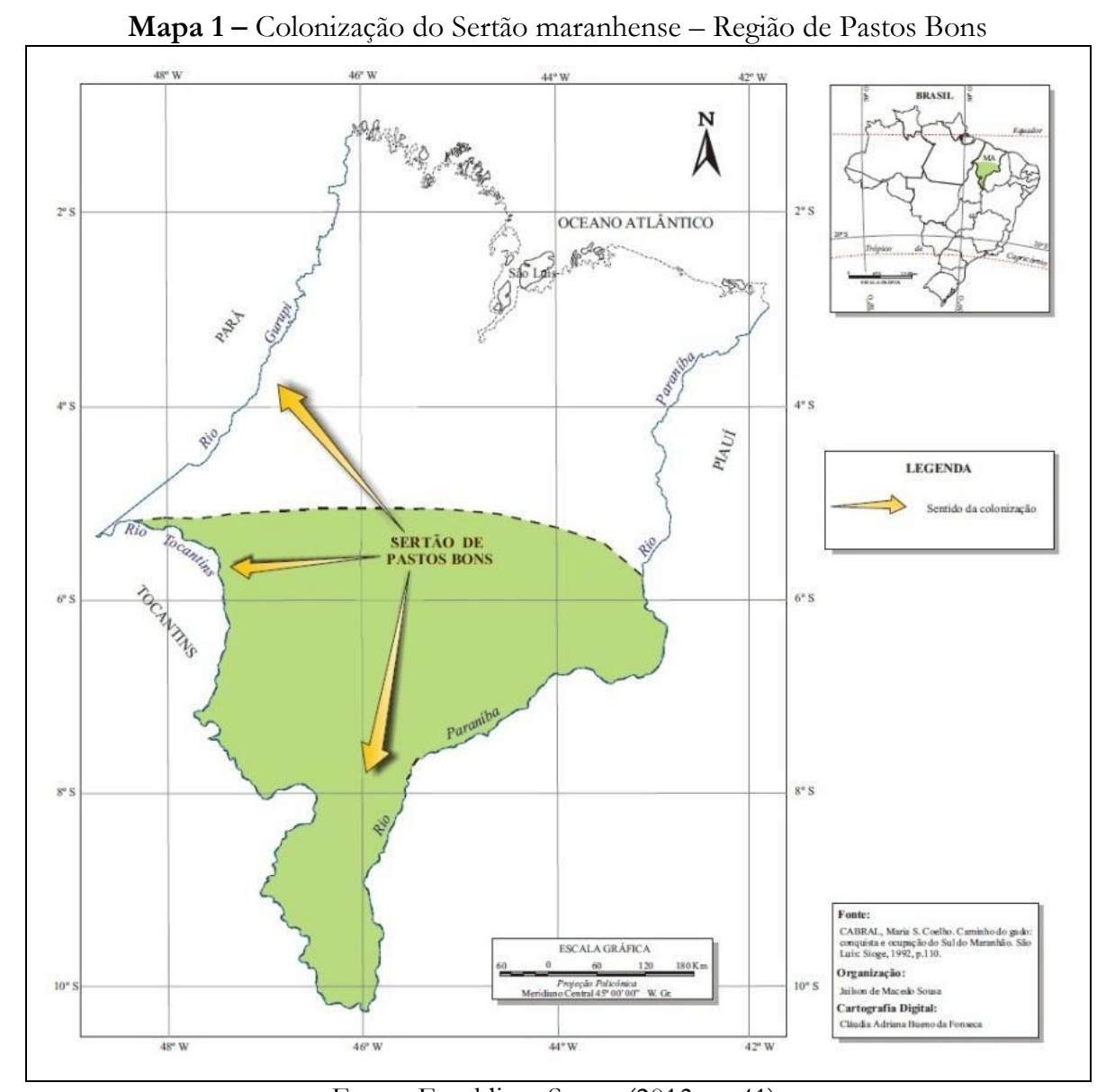

Fonte: Franklin e Sousa (2013, p. 41). 
| O rural e o urbano no Maranhão Meridional: apontamentos a partir da Região Geográfica Intermediária de Imperatriz |

| Helbaneth Macêdo Oliveira |

No entanto, isso vem a mudar na segunda metade do século XX com a abertura da estrada que liga Imperatriz a Grajaú em 1953, e posteriormente no contexto das políticas públicas de integração nacional com a abertura da Rodovia Belém-Brasília, irrompendo definitivamente o isolamento da região junto com a integração da Amazônia ao restante do país (FRANKLIN; SOUSA, 2013). Diante disso constata-se como a porção Meridional do Maranhão foi se desenvolvendo no transcorrer do tempo com uma história inicial de abandono por parte do estado, para posteriormente participar de forma pungente da inserção do território à reprodução do capital, uma vez que, é importante frisar, o sul do Maranhão faz parte da Amazônia Oriental, logo a porta de entrada para diversas ações direcionadas à Amazônia como um todo.

No contexto do processo de formação socioterritorial da Amazônia, além das diversas políticas públicas voltadas para esta área, a presença dos diversos ciclos econômicos são fundamentais para a compreensão desta área, tais como o ciclo da madeira, do arroz, do ouro (Serra Pelada), dentre outros. É justamente neste pormenor que Becker (2009) vai apontar uma particularidade, a presença dos "surtos" que fomentaram a criação e crescimento de diversas cidades amazônicas. No caso da região estudada, Imperatriz beneficiou-se destes, multiplicando seu quantitativo populacional, uma vez que era rota de passagem para os fluxos de pessoas e mercadorias direcionadas à Amazônia.

Assim sendo, tendo em vista o que já foi dito explica-se que o recorte regional aqui adotado (a Região Intermediária de Imperatriz), é pensado segundo a ótica desenvolvida por Santos (2014) ao explicar a complexidade das relações envolvidas em uma região, pois a mesma insere-se no contexto global de produção do espaço, que segundo ele:

Compreender uma região passa por entender como funciona a economia em
nível mundial e rebatê-la no território de um país, com a intermediação do
Estado, das demais instituições e do conjunto de agentes da economia, a
começar pelos seus atores hegemônicos. Estudar uma região significa penetrar
num mar de relações, formas, funções, organizações, estruturas etc., com seus
mais distintos níveis de interação e contradição. Se o espaço se torna uno para
atender às necessidades de uma produção globalizada, as regiões aparecem
como as diferentes versões da mundialização. Esta não garante a
homogeneidade, mas, ao contrário, instiga diferenças, reforça-as e até mesmo
depende delas. Quanto mais os lugares se mundializam, mais se tornam
singulares e específicos, isto é, únicos (SANTOS, 2014, p. 52-53).

Foi no sentido de se refletir sobre a região pelo viés de suas relações que interpretamos a porção meridional do Maranhão, no recorte da Região Intermediária de Imperatriz. Aqui se reconhece, conforme colocou Santos (2014), que as diferenças também apresentam um caminho para a autoafirmação e identificação da região, por isso a próxima 
| O rural e o urbano no Maranhão Meridional: apontamentos a partir da Região Geográfica Intermediária de Imperatriz|

| Helbaneth Macêdo Oliveira |

seção procura detalhar o recorte espacial da pesquisa, apresentando os principais dados que podem corroborar para se entender a porção sul do Maranhão.

\section{A REGIÃO GEOGRÁFICA INTERMEDIÁRIA DE IMPERATRIZ: conhecendo a} dinâmica do Sul Maranhense

As Regiões Intermediárias fazem parte da nova classificação do IBGE (2017), sendo que o nome dado a estas se refere ao município de maior pungência na questão regional, ou seja, o polo de atração de investimentos e fluxos em uma rede de cidades. No caso da Região Intermediária de Imperatriz encontra-se no município homônimo a identificação que a nomeia. Imperatriz se apresenta no contexto do estado enquanto o segundo maior município em quantitativo populacional, atrás apenas da capital. Neste sentido afirma-se que nesta região intermediária encontra-se também a Região Metropolitana do Sudoeste Maranhense (RMSM), criada pela Lei Complementar Estadual $\mathrm{n}^{\circ}$ 89, de 17 de novembro de 2005, sendo composta por oito municípios (Imperatriz, João Lisboa, Senador La Roque, Buritirana, Davinópolis, Governador Edison Lobão, Montes Altos e Ribamar Fiquene).

Assim, a localização espacial da Região Intermediária de Imperatriz é evidenciada pelo Mapa 2, no qual se confirma que, territorialmente falando, a maior parte do sul do Maranhão encontra-se circunscrita à área desta região intermediária. 
| O rural e o urbano no Maranhão Meridional: apontamentos a partir da Região Geográfica Intermediária de Imperatriz|

| Helbaneth Macêdo Oliveira |

Mapa 2 - Localização geográfica da Região Intermediária de Imperatriz - 2019

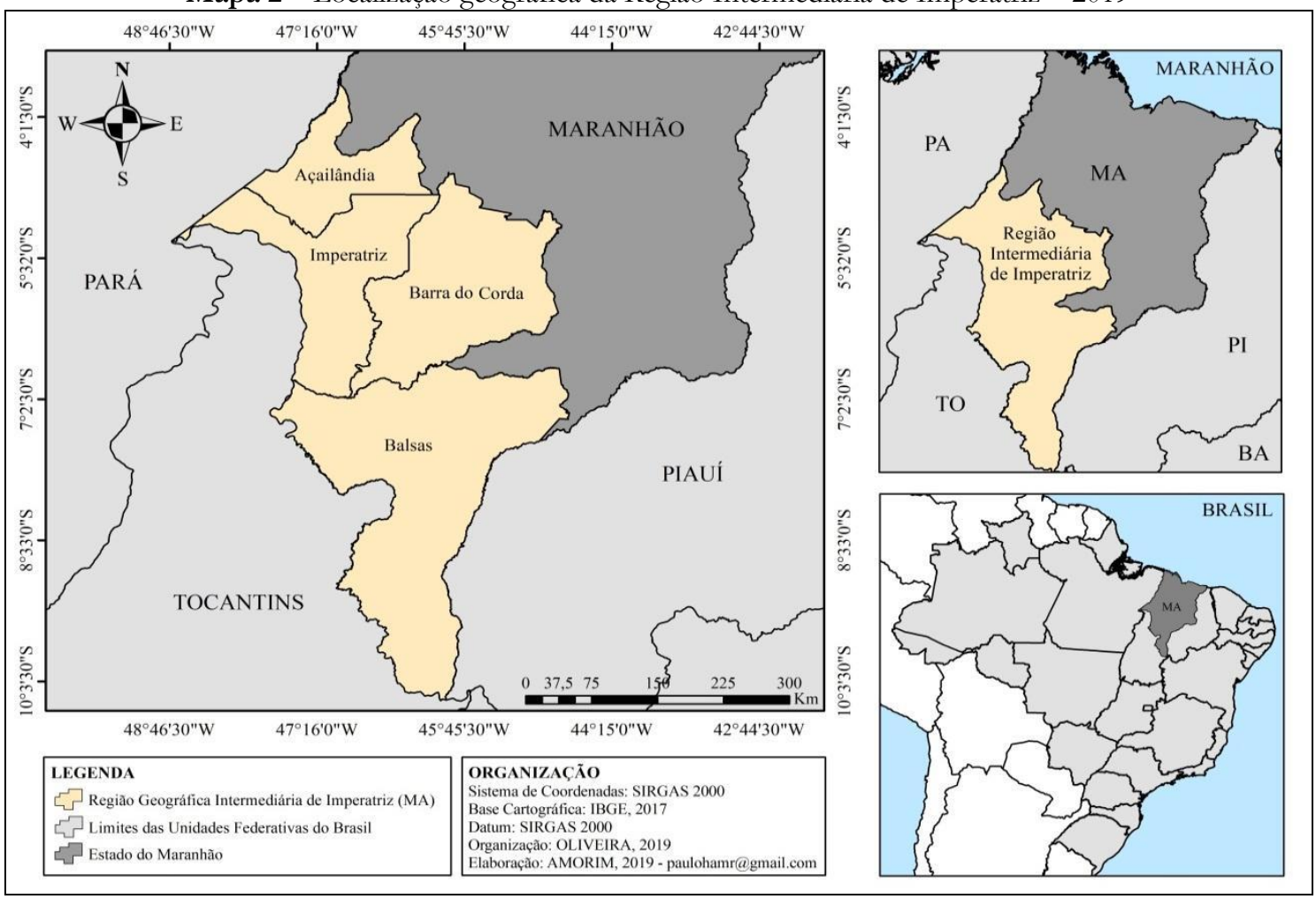

Fonte: IBGE (2017). Organização: A autora (2019).

Dessa feita, coloca-se que a origem do nome que adjetiva a região, objeto do presente estudo, refere-se à cidade que polariza sua dinâmica no contexto de sua rede, a qual diz respeito a Imperatriz ${ }^{4}$. Esta cidade apresenta um contingente populacional de 258.016 habitantes de acordo com estimativa do IBGE para 2018, uma densidade populacional de 188,47 hab. $/ \mathrm{km}^{2}$, estando situada à margem direita do rio Tocantins, onde também faz divisa com o estado do Tocantins.

A cidade também é adjetivada de princesa do Tocantins e portal da Amazônia (dada sua localização no extremo leste do bioma amazônico, classificado por Becker (1982) enquanto Amazônia Oriental). A mesma faz ligação com o restante do estado por meio da Rodovia Belém-Brasília (BR-010) que corta seu espaço intraurbano e pela rodovia MA-122; já com o estado do Tocantins a cidade faz ligação por meio da ponte estaiada Dom Affonso Felippe Gregory que se interliga com a TO-126, além da tradicional navegação fluvial.

Por conseguinte, a fim de pormenorizar as principais características da Região Intermediária de Imperatriz, a Tabela 1 demonstra os aspectos quantitativos desta referente à quantidade de municípios, população, densidade demográfica e área, utilizando-se para

${ }^{4} \mathrm{O}$ nome da cidade de Imperatriz foi dado em homenagem à Imperatriz Teresa Cristina, esposa de D. Pedro II. 
|O rural e o urbano no Maranhão Meridional: apontamentos a partir da Região Geográfica Intermediária de Imperatriz|

| Helbaneth Macêdo Oliveira |

isso as suas quatro Regiões Imediatas, as quais são: Região Imediata de Imperatriz, Região Imediata de Balsas, Região Imediata de Barra do Corda e a Região Imediata de Açailândia.

Tabela 1 - Região Intermediária de Imperatriz - caracterização geral das suas quatro Regiões imediatas, 2019

\begin{tabular}{|c|c|c|c|c|}
\hline Região Geográfica Imediata & $\begin{array}{c}\mathrm{N}^{\mathrm{o}} \text { de } \\
\text { municípios }\end{array}$ & População & $\begin{array}{c}\text { Densidade } \\
\text { Demográfica } \\
\left(\mathrm{hab} . / \mathrm{km}^{2}\right)\end{array}$ & $\begin{array}{l}\text { Área } \\
\left(\mathrm{km}^{2}\right)\end{array}$ \\
\hline Região Imediata de Imperatriz & 17 & 509.243 & 25,13 & $25.916,4$ \\
\hline Região Imediata de Balsas & 12 & 209.968 & 3,97 & $56.981,6$ \\
\hline Região Imediata de Barra do Corda & 9 & 254.787 & 7,69 & $33.375,6$ \\
\hline Região Imediata de Açailândia & 5 & 232.867 & 14,98 & $15.358,4$ \\
\hline Total & 43 & 1.206 .685 & 12,94 & 131.632 \\
\hline
\end{tabular}

Fonte: IBGE, Censo Demográfico de 2010. Organização: A autora (2019).

Analisando os dados apresentados pela Tabela 1, temos que a Região Intermediária de Imperatriz é composta por 43 municípios, um quantitativo populacional de 1.206.685, densidade demográfica de 12,94 hab. $/ \mathrm{km}^{2}$ e uma área de $131.632 \mathrm{~km}^{2}$. Onde, no conjunto das regiões imediatas a, de Imperatriz tem destaque e apresenta o maior número de municípios, de população e de densidade demográfica. Já no quesito extensão territorial, a Região Imediata de Balsas consta com a maior área, onde se destaca que apenas o município de Balsas apresenta a maior área dentre todos os municípios da região (com 13.141,70 km²), daí se correlacionar a presença da sojicultora como atividade produtiva predominante desta.

Observando que a temática do urbano e do rural faz parte deste trabalho, apresenta-se assim o detalhamento referente aos municípios componentes da região intermediária em estudo, apontando na Tabela 2 a porcentagem da população que é distribuída nas zonas urbanas e rurais, o quantitativo total destas no último censo do IBGE e sua estimativa para 2018.

Tabela 2 - Região Intermediária de Imperatriz - identificação percentual da população urbana, rural e total de suas regiões imediatas, 2019.

\begin{tabular}{l|c|c|c|c|c|c}
\hline \multirow{2}{*}{ Região Geográfica Imediata } & \multicolumn{5}{|c|}{ População (2010) } & \multirow{2}{*}{$\begin{array}{c}\text { População } \\
(\mathbf{2 0 1 8} *\end{array}$} \\
\cline { 2 - 7 } & Urbana & $\mathbf{0}$ & Rural & $\mathbf{0}$ & Total & \\
\hline Região Imediata de Imperatriz & 388.690 & 48 & 120.553 & 30 & 509.243 & 540.523 \\
\hline Região Imediata de Balsas & 145.402 & 18 & 64.556 & 16 & 209.968 & 225.594 \\
\hline Região Imediata de Barra do Corda & 123.052 & 15 & 131.735 & 33 & 254.787 & 273.463 \\
\hline Região Imediata de Açailândia & 149.933 & 19 & 82.934 & 21 & 232.867 & 254.543 \\
\hline \multicolumn{1}{c|}{ Total } & $\mathbf{8 0 7 . 0 7 7}$ & $\mathbf{1 0 0}$ & $\mathbf{3 9 9 . 7 7 8}$ & $\mathbf{1 0 0}$ & $\mathbf{1 . 2 0 6 , 8 6 5}$ & $\mathbf{1 . 2 9 4 , 1 2 3}$ \\
\hline
\end{tabular}

*Estimativa do IBGE para 2018. Fonte: IBGE, Censo Demográfico de 2010 e estimativa populacional para 2018. Organização: A autora (2019).

Os dados expostos evidenciam que a Região Intermediária de Imperatriz apresentou em 2010 um percentual de população urbana de 66,88\% (807.077 habitantes), 
| O rural e o urbano no Maranhão Meridional: apontamentos a partir da Região Geográfica Intermediária de Imperatriz|

| Helbaneth Macêdo Oliveira |

bem superior à da população rural com 33,12\% (399.778 habitantes), perfazendo um total de 1.206,865 habitantes, com uma margem crescimento em 2018 de 87.438 habitantes. Logo, conjectura-se que a distribuição da população mantém a relação urbana/rural similar à encontrada em 2010. A maioria das regiões imediatas apresenta um maior percentual da população urbana em relação à rural (à exceção da Imediata de Barra do Corda), com destaque para a Região Imediata de Imperatriz, notadamente, o município de Imperatriz com 94,7\% (234,547 habitantes) da sua população urbana, enquanto que apenas 5,3\% (12.958 habitantes) são residentes na zona rural, segundo o IBGE (2010).

Estudando melhor as cidades da Região Intermediária de Imperatriz, um dado é de particular interesse, o qual se refere ao porte das cidades. Para isso, este estudo procurou também evidenciar essa malha urbana, identificando três tipologias de cidades: as situadas entre 4.000 e 50.000 habitantes (uma vez que o menos populoso, que é São Pedro dos Crentes, possui segundo o último censo 4.425 habitantes), as situadas entre $50.000 \mathrm{e}$ 100.000 habitantes e os municípios com população entre 100.000 e 500.000 habitantes, conforme detalha o Gráfico 1 a seguir.

Gráfico 1 - Região Intermediária de Imperatriz - quantitativo e tipologia dos municípios segundo as quatro regiões imediatas, 2019.

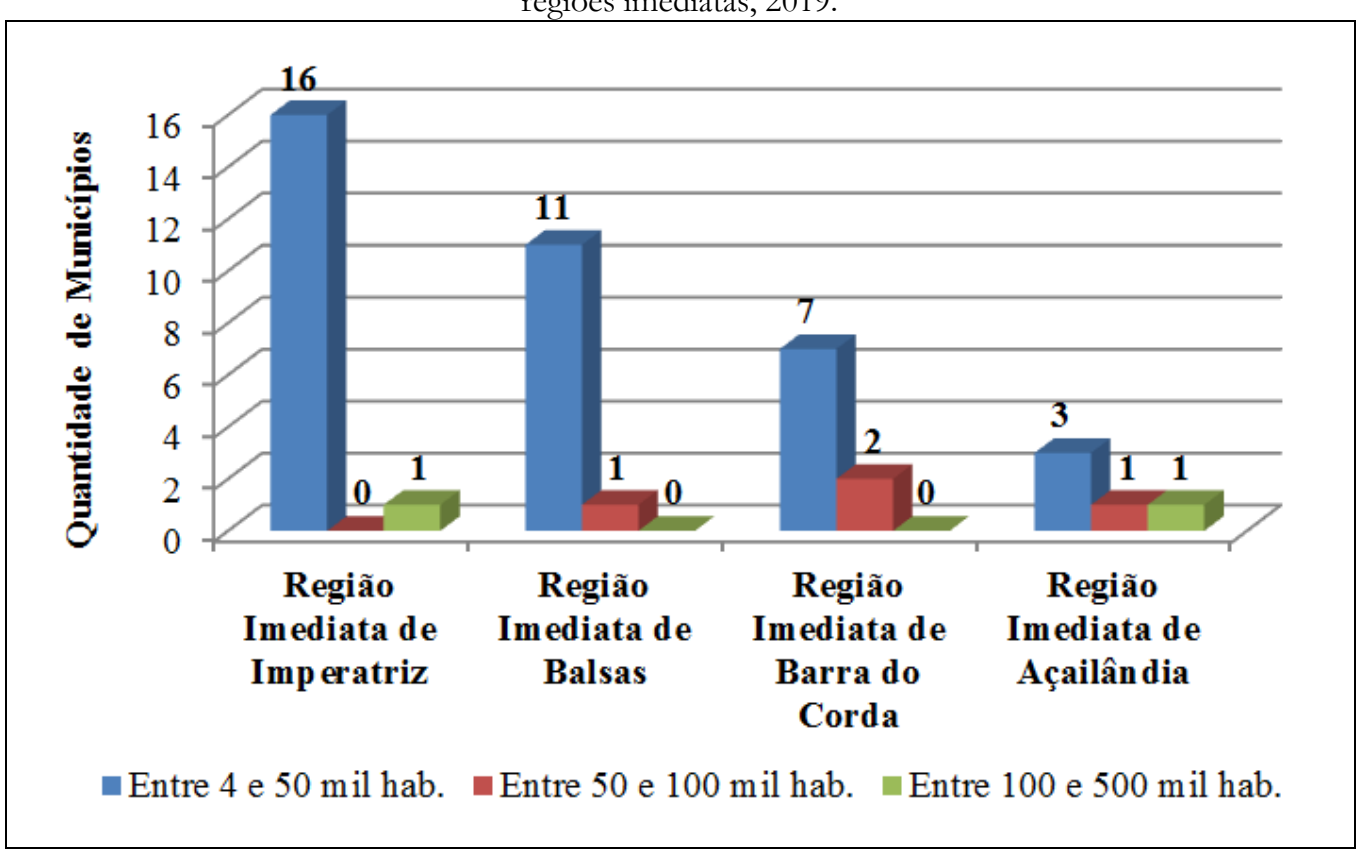

Fonte: IBGE, Censo Demográfico de 2010. Organização: A autora (2019).

O que pode ser observado diante do Gráfico 1 é que a maior parte dos municípios componentes da Região Imediata de Imperatriz está inserida na categoria de cidades pequenas (para um aprofundamento sobre o estudo de cidades pequenas aponta-se os trabalhos de Sposito e Jurado da Silva (2013); Fresca (2010) e Endlich (2009) como referências), uma vez que o IBGE as classifica como todas as cidades que possuem até 100 
|O rural e o urbano no Maranhão Meridional: apontamentos a partir da Região Geográfica Intermediária de Imperatriz|

| Helbaneth Macêdo Oliveira |

mil habitantes, logo, as duas das três categorias que evidenciamos. Optamos por subdividir essas cidades pequenas em duas categorias para melhor entender sua distribuição na região, onde apreendeu-se que as cidades entre 4.000 e 50.000 habitantes são as de prevalência em todas as regiões imediatas, com destaque para a Imediata de Imperatriz, seguida da Região Imediata de Balsas, Barra do Corda e Açailândia.

São poucas as cidades com população entre 50.000 e 100.000 habitantes, apenas quatro cidades foram encontradas: na Região Imediata de Barra do Corda identificou-se Barra do Corda e Grajaú; na Região Imediata de Balsas apenas Balsas; e na Região Imediata de Açailândia a cidade de Buriticupu. Já referindo-se às cidades de porte médio, apenas duas cidades foram identificadas em toda a região intermediária, Imperatriz e Açailândia, que nomeiam suas respectivas regiões imediatas, as quais também são consideradas cidades médias, de acordo com os estudos de Franklin e Sousa (2013), Sousa (2015), Carvalho e Oliveira (2015).

Diante do panorama das cidades constituintes da Região Intermediária de Imperatriz, importa também apresentar um pouco desta dinâmica regional com base nos fluxos econômicos que percorrem este espaço, base para a construção e manutenção desta rede de cidades. Neste sentido, a Tabela 3 apresenta o Produto Interno Bruto (PIB) da região distribuído segundo os valores agregados dos três principais setores econômicos: agropecuária, indústria e serviços.

Tabela 3 - Região Intermediária de Imperatriz - participação do PIB* de suas Regiões Imediatas para a economia do Maranhão, e os Valores Agregados (VA) por setor, 2019.

\begin{tabular}{|c|c|c|c|c|c|}
\hline $\begin{array}{c}\text { Região Geográfica } \\
\text { Imediata }\end{array}$ & $\begin{array}{c}\text { PIB } \\
(\mathrm{mil} \mathrm{R} \$)\end{array}$ & $\begin{array}{c}\% \\
\text { do PIB }\end{array}$ & $\begin{array}{c}\text { VA } \\
\text { Agropecuária } \\
\text { (mil R\$) }\end{array}$ & $\begin{array}{l}\text { VA Indústria } \\
\text { (mil R\$) }\end{array}$ & $\begin{array}{c}\text { VA } \\
\text { Serviços } \\
(\mathrm{mil} \mathrm{R} \$) \\
\end{array}$ \\
\hline $\begin{array}{l}\text { Região Imediata de } \\
\text { Imperatriz }\end{array}$ & 9.157 .781 & 12 & 520.560 & 2.553 .721 & 3.793 .131 \\
\hline $\begin{array}{c}\text { Região Imediata de } \\
\text { Balsas }\end{array}$ & 5.233 .413 & 7 & 2.128 .967 & 390.341 & 1.767 .418 \\
\hline $\begin{array}{c}\text { Região Imediata de } \\
\text { Barra do Corda }\end{array}$ & 1.731 .377 & 2 & 313.102 & 106.812 & 551.122 \\
\hline $\begin{array}{c}\text { Região Imediata de } \\
\text { Açailândia }\end{array}$ & 3.039 .017 & 4 & 397.990 & 759.944 & 985.904 \\
\hline Total & 19.161.588 & 25 & 3.360 .619 & 3.810 .818 & 7.097 .575 \\
\hline Maranhão & 78.475 .994 & 100 & 7.242.279 & 13.709 .748 & 30.615 .338 \\
\hline
\end{tabular}

*PIB a preço corrente. OBS: No valor total do PIB municipal está agregado também o valor dos impostos, não exemplificado aqui como um setor. Fonte: Instituto Maranhense de Estudos Socioeconômicos e Cartográficos (IMESC, 2016); IBGE, 2016. Organização: A autora (2019).

Mediante as informações apresentadas na Tabela 3 muitas inferências podem ser feitas, das quais inicia-se apontando que a Região Intermediária de Imperatriz (uma das 
| O rural e o urbano no Maranhão Meridional: apontamentos a partir da Região Geográfica Intermediária de Imperatriz|

| Helbaneth Macêdo Oliveira |

cinco do Maranhão) responde economicamente por cerca de $25 \%$ do PIB estadual. A importância da região estudada pode ser vista quando se observa que, dentre os dez municípios com maior participação no PIB estadual, três encontram-se na Região Intermediária de Imperatriz, sendo eles: Imperatriz em segundo lugar, Balsas em terceiro e Açailândia em quarto.

A composição do PIB da Região Intermediária de Imperatriz, observando-se os setores econômicos, tem na oferta de serviços uma forte contribuição (39\% do total do PIB) com aproximadamente o dobro do valor atribuído ao setor da agropecuária e indústria somados, tendência esta que o estado também apresenta. Com isso, detalhando-se um pouco mais o PIB da região intermediária de Imperatriz e, segundo os dados do IBGE e do Instituto Maranhense de Estudos Socioeconômicos e Cartográficos (IMESC), é possível apresentar algumas colocações.

O Setor Terciário tem na Região Imediata de Imperatriz a maior contribuição seguida da Imediata de Balsas, sendo que, no ranking estadual dentre os dez municípios que mais contribuíram, três encontram-se nesta região, sendo eles: Imperatriz em segundo lugar, Balsas em terceiro e Açailândia em sétimo. As três cidades cooperam na oferta de serviços com atividades tais como o comércio, educação, saúde, manutenção e reparação de veículos automotores e motocicletas, além da administração pública.

Quanto ao Setor da Indústria, o segundo lugar em contribuição para o PIB da Região Intermediária de Imperatriz, tem destaque a Imediata de Imperatriz seguida da Imediata de Açailândia. Sendo que, no ranking dos dez municípios com maior participação estadual neste setor encontram-se três: Imperatriz em segundo lugar com atividades referentes à Indústria de Transformação e da Construção Civil; Açailândia em quarto lugar também com a Indústria de Transformação (Metalurgia básica) e Construção Civil; e, em quinto lugar, Estreito com a produção e distribuição de eletricidade, com destaque para a geração de energia hidrelétrica que entrou em operação no ano de 2010.

Já no que tange ao Setor da Agropecuária tem destaque em primeiro lugar a Imediata de Balsas e, posteriormente, a de Imperatriz. Onde, dentre os dez municípios que mais contribuem para este setor no estado, sete fazem parte da Região Intermediária de Imperatriz, sendo quatro componentes da Imediata de Balsas (Balsas, Tasso Fragoso, São Raimundo das Mangabeiras e Alto Parnaíba), dois da Imediata de Açailândia (Açailândia e Bom Jesus das Selvas) e um componente da Imediata de Imperatriz (Amarante do Maranhão).

A Região Imediata de Balsas destaca-se com forte cultivo do algodão, soja (principalmente), cana-de-açúcar e milho, área maranhense que participa da junção de 
|O rural e o urbano no Maranhão Meridional: apontamentos a partir da Região Geográfica Intermediária de Imperatriz|

| Helbaneth Macêdo Oliveira |

municípios componentes do MATOPIBA5 . Já na Imediata de Açailândia, a pecuária e lavoura temporária tem destaque, com a criação de bovinos e o cultivo de milho. E, na Imediata de Imperatriz, apenas a pecuária e a lavoura temporária.

Observando o peso dos setores econômicos na composição do PIB da Região Intermediária de Imperatriz é que se faz um apanhado geral, melhor exemplificado no Gráfico 2. Onde se procura demonstrar o percentual de participação de cada setor nas quatro regiões imediatas.

Gráfico 2 - Região Intermediária de Imperatriz - participação percentual dos setores econômicos nas quatro regiões imediatas, 2019.

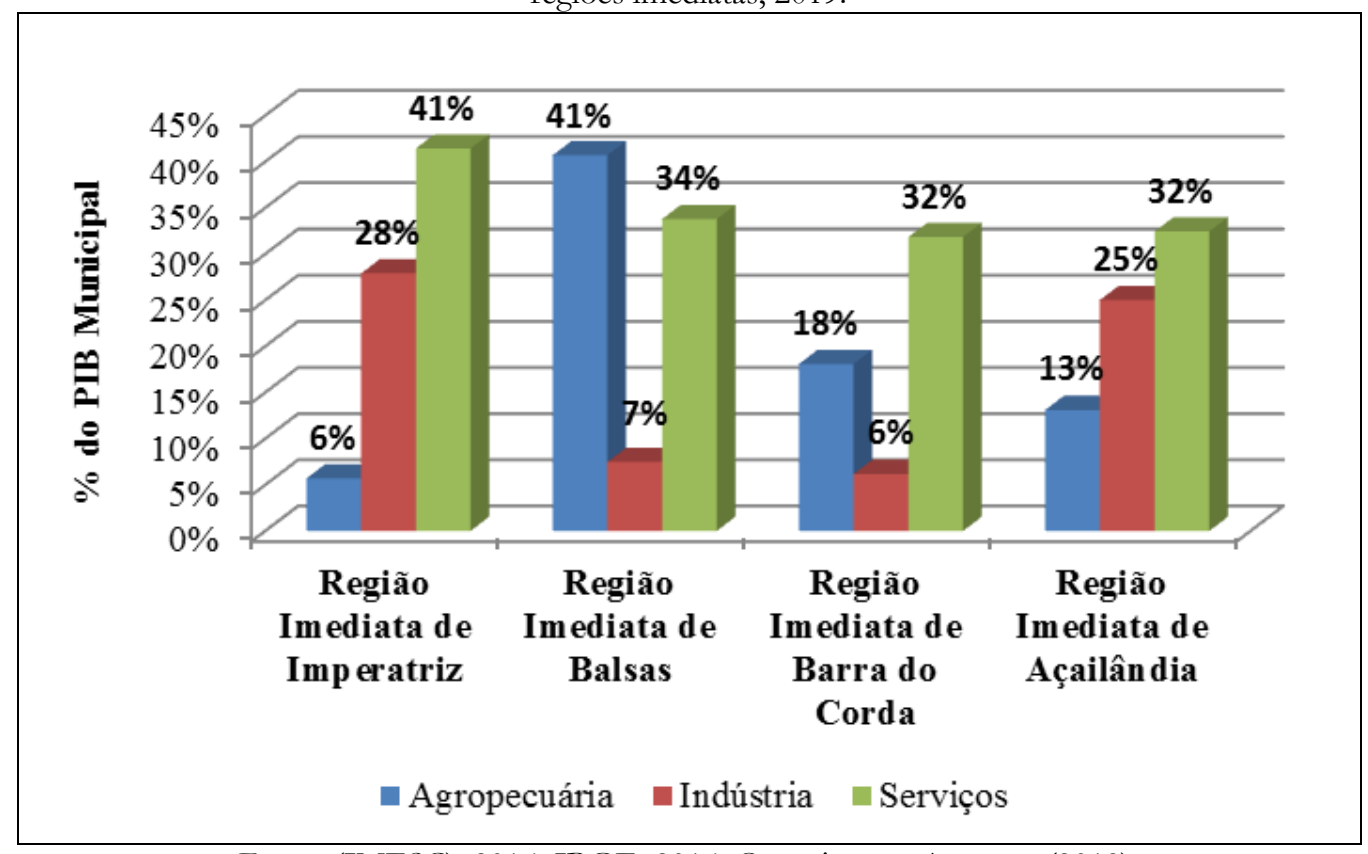

Fonte: (IMESC), 2016; IBGE, 2016. Organização: A autora (2019).

Percebe-se que, olhando para as regiões imediatas, um quadro é desenhado e merece atenção. O setor de serviços destaca-se em todas as regiões imediatas, excetuandose a Região Imediata de Balsas que tem na agropecuária a primeira colocação quanto ao peso do PIB desta região, o que se associa à forte presença da agricultura para exportação com as culturas da soja, cana-de-açúcar, algodão e milho. Enquanto que o setor secundário destaca-se nas Regiões Imediatas de Imperatriz e Açailândia com a forte presença da indústria da transformação e da construção civil.

Sob o mesmo ponto de vista se apresenta também, no processo de identificação da Região Intermediária de Imperatriz, o PIB per capita de seus principais municípios na classificação do estado, onde a porção sul tem proeminência. Isso porque dentre os dez

\footnotetext{
5 MATOPIBA é um termo formado pelas abreviaturas dos estados componentes da região de fronteira agrícola no país, atualmente compostas pelos estados do Maranhão (MA), Tocantins (TO), Piauí (PI) e Bahia (BA).
} 
| O rural e o urbano no Maranhão Meridional: apontamentos a partir da Região Geográfica Intermediária de Imperatriz|

| Helbaneth Macêdo Oliveira |

municípios do Maranhão com maior PIB per capita (entre $\mathrm{R} \$ 15.214,33$ mil e $\mathrm{R} \$$ 89.606,91 mil) encontram-se sete participantes da região em estudo, sendo eles: três municípios da Imediata de Balsas (Tasso Fragoso em segundo lugar, Balsas em sexto e São Raimundo das Mangabeiras em sétimo); três municípios na Imediata de Imperatriz (Davinópolis em terceiro lugar, Imperatriz em quarto e Porto Franco em oitavo); e por último na Imediata de Açailândia, sua cidade polo em décimo lugar.

Enfim, a dinâmica do Sulmaranhense se apresenta no contexto do estado enquanto uma região complexa em diversidade socioeconômica, com uma população em processo de crescimento, tendo primazia o predominante número de pequenas cidades, as quais se conectam a uma rede urbana onde a presença de cidades médias funciona como pontos nodais dos diversos fluxos que alimentam as trocas e transações que estruturam a dinâmica da Região Intermediária de Imperatriz.

Essa malha de cidades organiza assim a diversificação da economia Sulmaranhense que tem nos três principais setores uma dinâmica pungente, e que, devido à proximidade com os estados do Tocantins, Piauí e Pará, acentuam-se as relações desta com outras áreas fronteiriças do Maranhão, confluindo para o arranjo estadual.

\section{CONSIDERAÇÕES FINAIS}

Não obstante, o presente estudo sobre a Região Intermediária de Imperatriz pautou-se na identificação da sua dinâmica no contexto do estado do Maranhão, sua importância e características por meio do estudo de suas quatro regiões imediatas: Região Imediata de Imperatriz, Imediata de Balsas, Imediata de Açailândia e Imediata de Barra do Corda. Ambas nomeadas com base em seu município de maior polarização, com particularidades que foram estudadas por meio, inicialmente, da apresentação de seus respectivos quantitativos populacionais e, posteriormente, da porcentagem de suas populações residindo no campo e na cidade.

Ao se observar o peso dos três principais setores da economia na composição do PIB das regiões imediatas, observou-se que três das quatro regiões têm no setor terciário sua principal fonte de contribuição (Região Imediata de Imperatriz, Imediata de Açailândia e Imediata de Barra do Corda), enquanto que a Região Imediata de Balsas foi a única a apresentar maior participação do setor primário na economia. Já na indústria todas as regiões imediatas apresentam participação, com destaque para a Imediata de Imperatriz.

Este caminho corrobora para a diversificação das atividades econômicas na Região Intermediária de Imperatriz, onde segue-se o padrão encontrado também no estado, com o 
| O rural e o urbano no Maranhão Meridional: apontamentos a partir da Região Geográfica Intermediária de Imperatriz|

| Helbaneth Macêdo Oliveira |

setor de serviços enquanto o maior peso agregado para a economia da região, equivalendose aos outros dois setores somados. Assim, encontrou-se que a presença dos monocultivos de soja, cana-de-açúcar e milho possui uma importante contribuição, sendo por isso mesmo destaque no país enquanto participante do MATOPIBA, região esta que extrapola os limites estaduais.

O estudo permitiu observar que a Região Intermediária de Imperatriz tem uma considerável relevância para a economia estadual, sendo que a mesma abrange praticamente toda a porção meridional do estado, a qual diferencia-se do norte desde seu processo de formação socioterritorial à estruturação de sua dinâmica econômica. Diante disso, espera-se que o esforço aqui feito para demonstrar a relevância desta região seja um caminho inicial para a consecução de futuros estudos, visto que a Região Intermediária de Imperatriz, uma das cinco regiões intermediárias do Maranhão e situada no sul do estado, associa-se em muitos aspectos com os estados vizinhos dos quais destacamos Tocantins e Pará, apontando para uma dinâmica que vai além dos limites estaduais.

\section{AGRADECIMENTO}

À Coordenação de Aperfeiçoamento de Pessoal de Nível Superior - CAPES, pelo auxílio financeiro fornecido por meio da concessão da bolsa de estudo no curso de doutorado.

\section{REFERÊNCIAS}

BECKER, Bertha K. Geopolítica da Amazônia: a nova fronteira de recursos. Rio de Janeiro: Jorge Zahar Editores, 1982.

BECKER, Bertha K. Amazônia: geopolítica na virada do III milênio. Rio de Janeiro: Garamond, 2009.

CARNEIRO, Maria José. "Rural" como categoria de pensamento. RURIS, v. 2, n. 1, p. 09-38, mar. 2008.

CARVALHO, Carlota. O Sertão: subsídios para a história e a geografia do Brasil. 3. ed. Imperatriz: Ética, 2006.

CARVALHO, Sheryda Lila de Souza; OLIVEIRA, Adão Francisco de. Cidades médias a serviço do capital: o exemplo de Imperatriz (MA). Estudos Geográficos, Rio Claro, v. 13, p. 4-26, jan./jun. 2015. Disponível em: $<$ https://www.periodicos.rc.biblioteca.unesp.br/index.php/estgeo/article/view/9563/682 6). Acesso em: 16 jan. 2020.

ENDLICH, Ângela Maria. Pensando os papéis e significados das pequenas cidades. São Paulo: UNESP, 2009. 
|O rural e o urbano no Maranhão Meridional: apontamentos a partir da Região Geográfica Intermediária de Imperatriz |

| Helbaneth Macêdo Oliveira |

FRANKLIN, Adalberto; SOUSA, Jailson de Macêdo. Formação socioespacial da região Sulmaranhense: da emergência de Pastos Bons à constituição de uma região policêntrica. In: SOUSA, Jailson de Macedo (Org.). O regional e o urbano no sul do Maranhão: delimitações conceituais e realidades empíricas. Imperatriz, MA: Ética, 2013. p. 21-83.

FRESCA, Tânia Maria. Centros locais e pequenas cidades: diferenças necessárias. Mercator, v. 9, n. 20, p. 75-81, set./dez. 2010. Disponível em < http://www.mercator.ufc.br/mercator/article/view/398>. Acesso em: 18 jul. 2019.

IBGE - Instituto Brasileiro de Geografia e Estatística. Divisão regional do Brasil em regiões geográficas imediatas e regiões geográficas intermediárias. Rio de Janeiro: IBGE, 2017.

LOCATEL, Celso Donizete. Da dicotomia rural-urbano à urbanização do território no Brasil. Mercator, Fortaleza, v. 12, n. 2, p. 85-102, set. 2013. Disponível em < http://http://www.mercator.ufc.br/index.php/mercator/article/viewFile/1176/498>. Acesso em: 18 jul. 2019.

OLIVEIRA, Ariovaldo Umbelino de. Geografia agrária: perspectivas no início do Século XXI. In: OLIVEIRA, A. U. de; MARQUEZ, M. I. M. (Org.). O campo no Século XXI: território de vida, de luta e de construção da justiça social. São Paulo: Editora Casa Amarela; Editora Paz e Terra, 2004. p. 29-70.

IBGE - Instituto Brasileiro de Geografia e Estatística. Bases cartográficas contínuas Brasil. Rio de Janeiro: IBGE, 2017. Disponível em: $<\underline{\text { https://geoftp.ibge.gov.br/cartas e mapas/bases cartograficas continuas/bc250/versa }}$ o2019/ >Acesso em: jul. 2019.

IMESC - Instituto Maranhense de Estudos Socioeconômicos e Cartográficos. Produto Interno Bruto dos Municípios do Estado do Maranhão: 2016. São Luís: IMESC, 2016.

RUA, João. A ressignificação do rural e as relações cidade-campo: uma contribuição geográfica. Revista da ANPEGE, v. 2, n. 02, p. 45-65, 2005.

SANTOS, Milton. A natureza do espaço: técnica e tempo, razão e emoção. 4. Ed. São Paulo: Edusp, 2017.

SANTOS, Milton. Metamorfoses do espaço habitado: fundamentos teóricos e metodológicos da geografia. 6. ed. São Paulo: Edusp, 2014.

SOUSA, Jailson de Macedo. Enredos da dinâmica urbano-regional Sulmaranhense: reflexões a partir da centralidade econômica de Açailândia, Balsas e Imperatriz. 2015. Tese (Doutorado em Geografia) - Instituto de Geografia, Universidade Federal de Uberlândia, Uberlândia, 2015.

SPOSITO, Eliseu Savério; JURADO DA SILVA, Paulo Fernando. Cidades Pequenas: perspectivas teóricas e transformações socioespaciais. Jundiaí: Paco Editorial, 2013.

SUZUKI, Júlio César. Modernização, território e relação campo-cidade: uma outra leitura da modernização da agricultura. In: MEDEIROS, R. M. V.; FALCADE, I. (Org.). Tradição versus tecnologia: as novas territorialidades do espaço agrário brasileiro. Porto Alegre: Editora da UFRGS, 2009. p. 241-253. 
| O rural e o urbano no Maranhão Meridional: apontamentos a partir da Região Geográfica Intermediária de Imperatriz|

| Helbaneth Macêdo Oliveira |

WANDERLEY, Maria de Nazareth Baudel. O mundo rural como um espaço de vida: reflexões sobre a propriedade da terra, agricultura familiar e ruralidade. Porto Alegre: Editora da UFRGS, 2009.

\section{Como citar este artigo:}

\section{ABNT}

OLIVEIRA, H. M. O rural e o urbano no Maranhão Meridional: apontamentos a partir da Região Geográfica Intermediária de Imperatriz. InterEspaço: Revista de Geografia e Interdisciplinaridade, v. 6, e202017, 2020. Disponível em: <http://dx.doi.org/10.18764/2446-6549.e202017>. Acesso em: 25 jan. 2020.

\section{APA:}

Oliveira, H. M. (2020). O rural e o urbano no Maranhão Meridional: apontamentos a partir da Região Geográfica Intermediária de Imperatriz. InterEspaço: Revista de Geografia e Interdisciplinaridade, v. 6, e202017. Recuperado em 25 janeiro, 2020, de http://dx.doi.org/10.18764/2446-6549.e202017

\section{cc) commons}

This is an open access article under the CC BY Creative Commons 4.0 license.

Copyright (C) 2020, Universidade Federal do Maranhão.

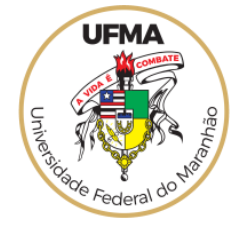

